\title{
RECENT ADVANCES IN WATER PURIFICATION EQUIPMENT
}

\author{
Major J. QUINN, B.A., M.B., B.Ch., B.A.O., D.P.H., D.T.M. \& H., D.I.H., R.A.M.C.
} Army School of Health*

SUMMARY: Two new water point sets are described.

As the two sets are almost identical except for the sizes of the various components the lightweight set only is described in detail. They provide for the treatment of water by sedimentation, filtration and chlorination. A feature novel to military field equipment is the employment of liquid chlorine for sterilization.

\section{Introduction}

Moving ahead with more modern and efficient methods of water purification and having in mind the present military policy of eliminating specialist vehicles in the field two new water point sets will, within the next year or so, be taken into use by the Services. Both sets have undergone extensive trials by a variety of units and with a small number of minor modifications they have been well received.

\section{Equipment}

The Standard Set will pump and purify water for battalion and brigade groups at the rate of at least 23 litres ( 5 gallons) per man per day. This equipment will be established and operated by the Royal Engineers and will produce 6,825 litres (1500 gallons) per hour.

The Lightweight Set will pump and purify water for company and platoon groups at the rate of at least 23 litres ( 5 gallons) per man per day. This equipment will usually be installed by Assault Pioneers or Royal Engineers and operated and maintained by units and sub-units of all arms. All Regimental trained water duty personnel must be capable of installing this set which is capable of producing 300 gallons per hour.

Both the Standard and Lightweight Set are transported in a $\frac{3}{4}$ ton long wheel base landrover or in a standard $\frac{3}{4}$ ton trailer. Four men are required to handle the Standard Set while two men are more than adequate for the lightweight Set.

\section{The lightweight water point set}

The suction head which is floated in the water source consists of a combined float and strainer attached to the suction hose. This hose is made up of a rigid P.V.C. spiral inside a plasticised P.V.C. covering and is non-collapsible; $2 \times 9$ metres (30 feet) lengths are provided.

The suction hose leads to the combined engine and pump (Fig. 1) which weighs 80 kilograms (180 pounds). The engine is a Petters, air-cooled, single cylinder diesel which uses about one pint of fuel per hour. The pump is capable of lifting water from at least 4.5 metres ( 15 feet) below its own level and delivering it through as much as 75 metres (250 feet) of hose against a static head of at least 30 metres (100 feet).

From the pump the water is conveyed in a collapsible delivery hose which has an outer P.V.C. coating and an inner rubber lining; $3 \times 3$ metres (10 feet) lengths and $12 \mathrm{x}$ 9 metres (30 feet) lengths are provided.

* Now D.A.D.A.H., South West District. 


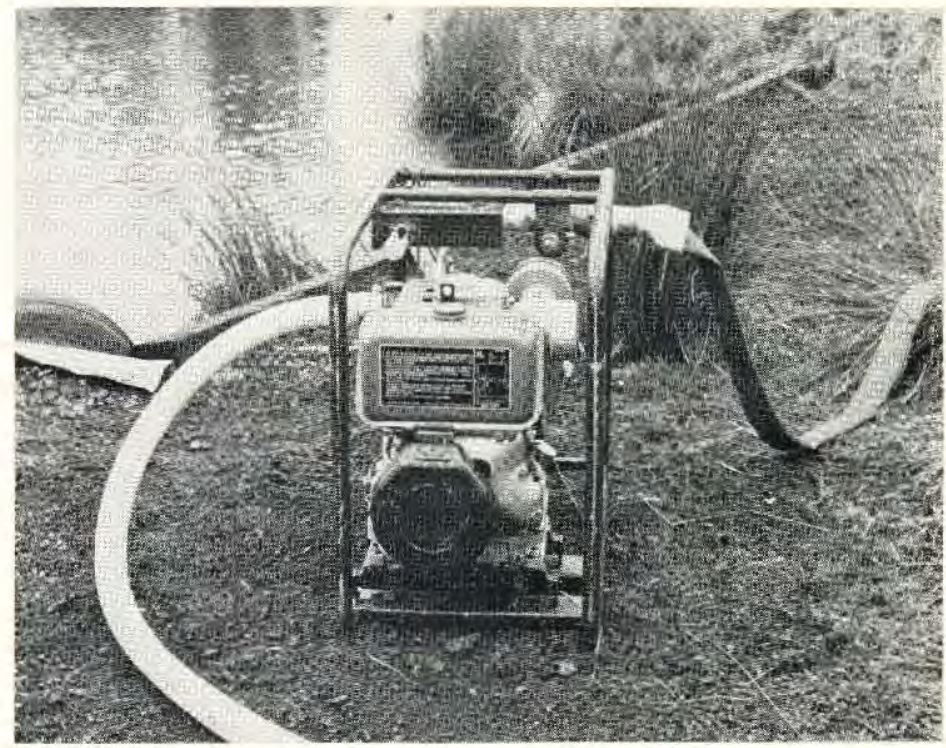

Fig. 1. Combined engine and pump of the lightweight water point set.

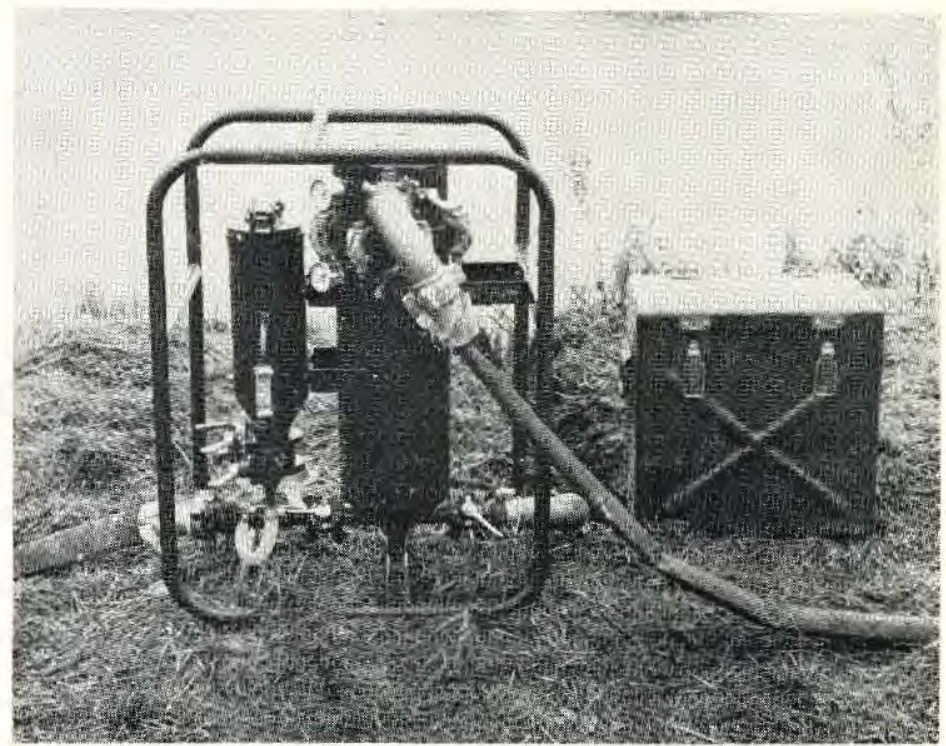

Fig. 2. Stella-Meta filtration unit.

The raw water arrives at the filtration unit which can be either a Vokes or a StellaMeta type. Each weighs 40 kilograms ( 90 pounds) (Fig. 2 shows a Stella-Meta filter). In each case the filter is charged with Kieselguhr powder which forms a coating on the candles through which the raw water is forced.

The filtered water now passes to the chlorinator (Fig. 3) which weighs 40 kilograms 


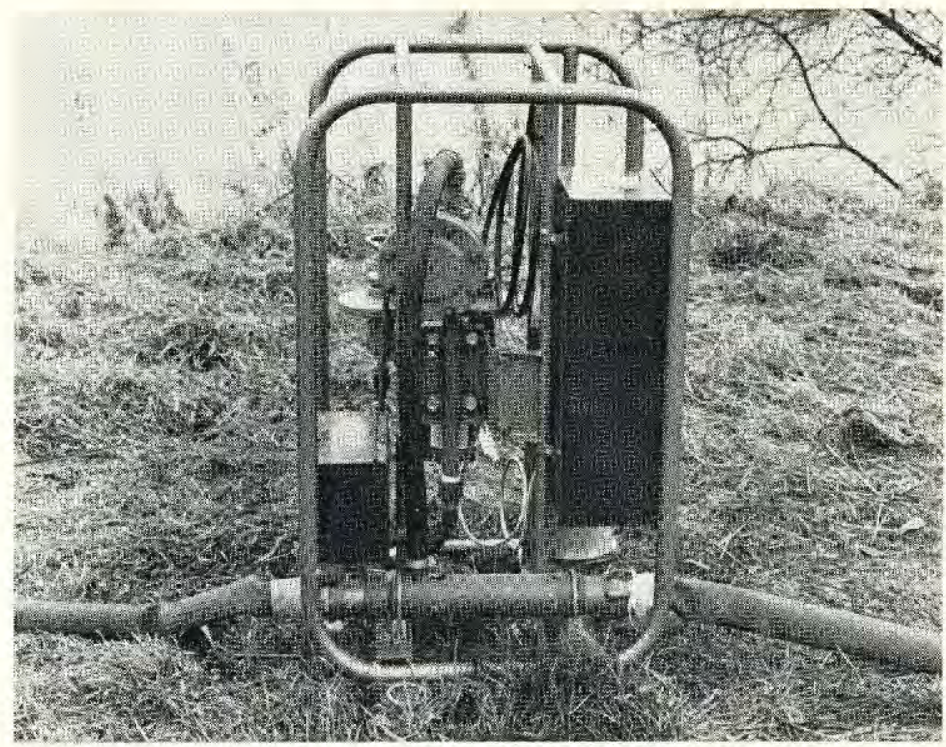

Fig. 3. Filtered water passing to the chlorinator.

(90 pounds). Chlorine gas is stored under pressure as a liquid in a cylinder. The gas is fed into the water through a regulator and Venturi tube. There is approximately 4.5 kilograms (10 pounds) of chlorine in the cylinder, sufficient to sterilise 291,000 litres (64,000 gallons) of water. A bottle of ammonia to check for leaks and a respirator are issued with the set.

From the chlorinator the treated water now passes to the storage tanks. There are two tanks to each set. Each tank has a capacity of 1,550 litres ( 340 gallons). The tanks are made of neoprene fabric and have an inflatable rubber collar, a cover with float, a foot pump, a repair outfit and a carrying bag.

The effectiveness of the sterilizing process is checked by the Palin DPD test using the No. 1 tablet and the Lovibond comparator. The aim is to have a residual chlorine of 2 p.p.m. after 30 minutes contact. The regulator on the chlorinator is adjusted until the correct residual is achieved. The excess chlorine is removed from the water before use by the addition of taste removing tablets.

The outlets of the storage tanks are connected to a manifold from which the water is dispensed to water bottles, jerrycans or any other suitable container. The Lightweight Set can be used without the chlorinator, sterilization being carried out in the storage tanks by the fixed dose chlorination method using water sterilizing powder.

\section{Conclusion}

The two new Water Point Sets represent a significant advance on existing water purification equipment which they will replace. They are easier to use, more reliable and much more efficient. It has been agreed that Regimental Water Duty personnel attending courses at the Army School of Health, R.A.M.C. Training Centre will soon be given instruction on the new equipment. 


\section{ROYAL ARMY MEDICAL CORPS OFFICERS' WIDOWS' \& ORPHANS' FRIENDLY SOCIETY}

PROVIDES BASIC LIFE ASSURANCE for the families of officers in the following privileged categories:-

R.A.M.C., R.A.D.C., and

Royal Naval Medical Service: Serving and retired regular officers, including cadets and short-service commissioned officers.

R.A.M.C. (V) and

R.A.D.C. (V): Serving officers.

Please ask the Secretary for details:

Kirkland House, Whitehall, London, S.W.1.

Tel: 01-930 1701 .

Saafi

SAVE on your new car or caravan with low-cost HP and big discounts on new cars and touring caravans.

can

help

SAVE up the deposit for a new car or caravan and reduce the HP cost.

SAVE for a home of your own. Naafi has made arrangements with Save and Prosper and Leicester Permanent Building Society for a house purchase plan on special terms and with life insurance. you

SAVE and prosper with Naafi's savings plan for the Forces. CIT Special arrangements with Scotbits Securities give you the CQVC benefit of regular investment in first-class business enterprises, and immediate life assurance at specially reduced rates.

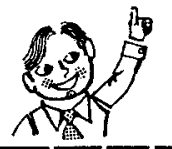

SAVE for the future with all forms of life assurance, including with-profits policies, all on advantageous terms.

For full details complete and post the coupon today.

Marketing Dept. MKG/C/6

Naafi London SEII

Rank

Name

(Block letters)

Address

(Block letters)

\begin{tabular}{l} 
New car $\quad$ for use in \\
\hline New caravan for use in \\
\hline for delivery at $\quad$ date \\
\hline Used car HP New car HP $\square$ Caravan HP \\
HP deposit saving \\
Savings Plan for the Forces $\square$ House purchase \\
Life assurance
\end{tabular}

Please tick box where appropriate. 